\title{
Momentum Effect: Evidence from the Vietnamese Stock Market*
}

\author{
Pascal Alphonse \\ Professor, University of Lille North of France - Skema Business School - LSMRC \\ Thu Hang Nguyen ${ }^{* *}$ \\ PhD Candidate, University of Lille North of France \\ Lecturer, Foreign Trade University, HCMC Campus, Vietnam
}

Received: Sep. 20, 2013 Accepted: October 31, 2013 Published: December 1, 2013

doi:10.5296/ajfa.v5i2.4310 URL: http://dx.doi.org/10.5296/ajfa.v5i2.4310

\begin{abstract}
This paper focuses on the profitability of momentum strategies in the Vietnamese stock market. The results assert that momentum occurs within small- and large- sized stock subsamples in the period prior to the Lehmann shock and does not exist in the remaining subsamples. Further tests point out that the occurrence of momentum follows market gains and is consistent with the overreaction hypothesis. The phenomenon is likely to be explained by the low individualism in the Vietnamese culture. Evidence on high volatility, low persistence and high correlation of stock returns is also found from the study.
\end{abstract}

Keywords: Market efficiency, Momentum, Vietnamese stock market, Investor behavior, Market state

\footnotetext{
* This article is a revised and expanded version of a paper entitled "Momentum effect in the Vietnamese stock market", presented at $2^{\text {nd }}$ Annual International Conference on Accounting and Finance (AF2012), Singapore and published in Procedia Economics and Finance 2 (2012).

** Corresponding author, email: nthuhang@hotmail.com
} 


\section{Introduction}

Levine (2001) asserts that a well-organized stock market promotes economic growth in developing countries by creating liquidity, improving risk diversification and corporate governance. These results explain the reasons for the establishment of Vietnamese stock market. Vietnam launched its first exchange in Hochiminh city in 2000 and the second one in Hanoi in 2005. Over a decade, the Vietnamese stock market has experienced significant growth. The number of listed stocks rose from two in 2000 to more than $700^{1}$ in 2012, while the total market capitalization of listed firms peaked a mark of 27.5 percent of GDP in 2007the year of market boom and decreased to 14.8 percent in $2011^{2}$. The market intensive development has raised a concern over its quality including liquidity, information disclosure and volatility. In Decision No 252/ QD-TTg ${ }^{3}$, which approves initiatives to develop the stock market over the period from 2011 to 2020, the government emphasizes the key targets of improving market liquidity and information disclosure, increasing the total market capitalization up to 70 percent of GDP and enhancing the operation efficiency of trading system. This means that Vietnam is aiming at a well-organized stock market in accordance with Levine (2001).Therefore, the question whether the market is efficient is important for both policy makers and researchers. Nguyen, Tran and Zeckhauser (2012) reject the semistrong form efficiency of the Vietnamese stock market. They discover extremely high abnormal returns of stocks prior to their split announcements, higher than their abnormal post-announcement returns, raising a concern over illegal insider trading in the market. Employing autocorrelation tests, runs tests and variance-ratio tests, Truong, Lanjouw and Lensink (2010) reject the weak-form efficiency of the market. However, as the authors examine a sample of only 5 stocks in the 2000-2004 period when the market has just been established, their results should be used with care. Our study also focuses on the weak-form efficiency with a sample ranging from 67 to 267 stocks listed on the Ho Chi Minh Stock Exchange (HOSE)-the main exchange of the Vietnamese stock market ${ }^{4}$ for the period from January 2007 to June 2012. We use a sample of weekly returns to increase the number of observations.

The weak-form efficiency implies that it is impossible to earn abnormal returns on the basis of past returns (Fama, 1970, 1991). The two diametrically opposed anomalies often found in a weak-form inefficient market with respect to past returns for different investment horizons are reversals and momentum. Prior literature shows that the former occurs in short-term for weekly returns (Lehmann, 1990) or in long-term (three to five years) for monthly returns (DeBond \& Thaler, 1985), whereas the latter happens in medium-term (from several to 12 months) for weekly returns (Gutierrez \& Kelley, 2008) or monthly returns (Jegadeesh \& Titman, 1993). This means that both reversals and momentum may appear in weekly returns. However, Gutierrez \& Kelley (2008) indicate that a brief reversal is present in the first two weeks after portfolio formation and easily offset by the following strong long-lasting momentum. This finding asserts that momentum, not reversals, is a dominant feature of weekly returns. Motivated by these results, using a sample of weekly returns, we concentrate

\footnotetext{
${ }^{1}$ As of 29 November, 2012, 308 listed firms on Ho Chi Minh Stock Exchange (retrieved from http://www.hsx.vn/hsx en ) and 395 on Hanoi Stock Exchange (retrieved from http://www.hnx.vn/en ).

2 According to the World Bank's data on market capitalization of listed companies (\% of GDP) (Retrieved from http://data.worldbank.org/indicator/CM.MKT.LCAP.GD.ZS )

${ }_{3}$ Retrieved from http://www.hsx.vn/hsx_en/Modules/Phapquy/Phapquy.aspx

${ }^{4}$ As announced on websites of the Hochiminh Stock Exchange (HOSE) (http://www.hsx.vn/hsx_en) and the Hanoi Stock Exchange (HNX) (http://www.hsx.vn/hsx_en), at the end of 2011, the total market capitalization of the two markets is 453,784 billion VND and 81,889 billion VND, respectively. This means that the HOSE accounts for 84 percent of the total market capitalization of the market.
} 
on the momentum effect. Employing the methodology initiated by Jegadeesh and Titman (hereafter JT) (1993), we find the occurrence of momentum in the short-run. The evidence also indicates that winner and loser returns are lowly persistent and highly volatile, but their strong correlation creates significant momentum profits.

The results from additional tests point out that momentum is confined to small- and large-sized subsamples in the period before the Lehmann shock. Especially, it follows short-term market gains and is consistent with the over-reaction hypothesis. This implies that after realizing market gains investors are more confident and overreact to news, which generates momentum and long-term reversals. However, the magnitude of reversals is very weak, which can be explained by the argument of Chui, Titman and Wei (2010) on individualism. The less individualistic investors who act less like the overconfident/self-attribution biased ones tend not to make investment decisions that produce momentum profits and reversals in long-term horizons. After short-term market declines or the Lehmann shock, momentum does not exist, which is similar to the finding of Chui, Titman and Wei (2000) on the absence of momentum in Asian markets for the period prior to the 1997- crisis.

The remainder of the paper is organized as follows: section 2 gives a brief review on momentum effect and its explanations; section 3 provides data description; section 4 illustrates methodology description; section 5 shows empirical results and section 6 concludes some findings.

\section{Literature review}

\subsection{Market efficiency and momentum evidence}

The efficient market hypothesis suggests that market is rational and security prices fully reflect all available information (Fama, 1970, 1991). However, Fama emphasizes that market efficiency is not testable because it should be tested in the context of a proper pricing model. This means that if anomalies are found in empirical studies, we merely infer that either the market is inefficient or the model is implausible. Put differently, it remains impossible to infer precisely the degree of market efficiency due to the joint-hypothesis problem (Fama, 1991). In fact, prior literature commonly sidesteps the issue of plausible models but concentrates on the anomalies. Amongst those, momentum has been debated widely since the publication of JT (1993). JT (1993) find medium-term return continuation in the US market for the period prior to 1989: the momentum strategies that long stocks with high returns over the past three to 12 months and short stocks with low returns over the same periods earn significantly positive profits. In their following research, JT (2001) report sustained momentum in the 1990s, but JT (2011) discover negative profits in 2008 and 2009.

Gutierrez and Kelley (2008) employ a sample of weekly returns of the US market from 1983 to 2003 and find a long-lasting stream of momentum that follows a brief reversal in the initial two weeks after portfolio formation. The momentum profits are sufficient enough to offset the initial reversal, resulting in significant momentum over the full year following portfolio formation.

Rouwenhorst (1998) focuses on international momentum strategies over twelve European markets from 1978 to 1995 and discovers medium-term momentum across markets and within each market except for Sweden. The momentum effect is examined in emerging and Asian markets as well, but is reported that the magnitude is weaker than that in the US and European markets. Rouwenhorst (1999) documents that momentum is present in an aggregate 
sample of 20 emerging markets, but with the samples of individual markets it is significantly positive for only six markets. Examining eight Asian markets, Chui et al. (2000) report that momentum within each country is rather weak: only the profit of Hong Kong market is significantly positive for the whole sample period, while the profits of Hong Kong, Malaysia, Singapore and Thailand are significantly positive for the pre-crisis period. With a bigger sample of 40 countries, Griffin, Ji and Martin (2003) confirm that momentum in Asian and emerging markets is relatively weak in comparison with that in the remaining areas.

\subsection{Explanations for momentum effect}

On the assumption that stock returns follow a simple one-factor model, JT (1993) decompose the profit into three components: the cross-sectional dispersion in expected returns, the serial covariance in factor returns and the serial covariance of the idiosyncratic components of security returns. If the momentum is caused by either the first or the second component, it can be considered as compensation for bearing systematic risk and is not regarded as an indication for market inefficiency. If it is driven by the third component, it is possible to conclude that the market is inefficient. JT (1993) provide evidence suggesting that momentum may arise from the last component, implying that the delayed price reactions to firm-specific information generate the profits. This result has two interpretations: one is the under-reaction of investors to firm-specific information and the other is the over-reaction that is eventually followed by reversals.

Departing from JT (1993)'s argument, on the assumption that the mean returns of individual stocks are stationary, Conral and Kaul (1998) assert that momentum profits are mainly driven by the cross-sectional variation in mean returns, that is, momentum reflects compensation for risk. Thus, the following studies such as JT (2001), Gutierrez and Kelley (2008) examine risk-adjusted profits under specific asset pricing models. Their results show that the momentum is still statistically significant after being accounted for risk, that is, the risk-based theory is unlikely to explain the effect. Hence, recent literature mainly relies on behavioral models to explain this phenomenon. There are three main hypotheses on investor behavior, which are considered to create momentum.

Firstly, Barberis, Shleifer and Vishny (1998) propose that conservatism bias causes investor under-reaction to news, which generates return momentum. Precisely, investors slowly change their beliefs in the face of news announcement, which creates stock abnormal returns. When the information is fully incorporated in prices, no further abnormal return exists.

Secondly, Daniel, Hirshleifer and Subrahmanyam (1998) argue that investor overconfidence and biased-self attribution create momentum. The study supposes that investors tend to be overconfident about their private information and overestimate its precision. Additionally, they asymmetrically react to their decision outcomes. They attribute successes to their skill and ascribe failures to external noise. Hence, the investors' confidence increases when the subsequent public information confirms their private news, which boosts the overreaction and produces momentum in stock returns. However, the momentum will eventually be reversed in the long run when the investors realize their errors.

Thirdly, Hong and Stein (1999) explain the short-term momentum and long-term reversals in asset markets as results of interaction between news watchers and momentum traders - the two types of agents in the market. The news watchers predict future returns based on their private fundamental information and do not pay attention to current or past prices, whereas the momentum traders trace profits based only on past price changes. Hong and Stein (1999) argue that if information spreads gradually across news watchers, that is, price under-reaction 
occurs in the short run, and then momentum traders can earn profits. However, their attempts to trace profits might push up the prices above the fundamental values, and then overreaction happens and leads to fundamental reversals in the long run.

Although Daniel et al. (1998) and Hong and Stein (1999) initiate from different assumptions on investor behavior, they have a similar inference on price behavior in the long run, which is a stream of overreaction followed by reversals. Consequently, there are two types of price behavior inferred from the three behavioral models: under-reaction and overreaction. JT (2001) provide evidence supporting the latter.

Upon the JT (1993)'s argument that momentum arises from the investors' delayed reactions to firm specific information, a number of studies have investigated the relationship between momentum and the factors relating to firm characteristics, information quality and behavioral biases. JT (2011) provide a precise review on these papers. Amongst those, Chordia and Shivakumar (2002), Chui et al. (2010), Cooper, Gutierrez Jr. and Hameed (2004), Du, Huang and Liao (2009) have some implications relating to our results. Chui et al. (2010) find that individualism is positively correlated with the degree of momentum and the magnitude of reversals tends to be higher in countries with higher individualism. Chordia and Shivakumar (2002) discover that momentum profits are positive only during expansionary periods and are negative or statistically insignificant during recession periods. Cooper et al. (2004) find a relationship between market states and momentum magnitude, which implies that the overreaction is greater when the market is up. Du et al. (2009) indicate that the poor performance of momentum in the Taiwan stock market relates to the down market states.

\section{Data}

We use a sample of simple weekly returns of stocks listed on the Ho Chi Minh Stock Exchange (HOSE) for the period between January 2007 and June 2012. The data was supplied by iTrade corporation- a data provider of the Vietnamese stock market. Although the HOSE had its first trading section on July $28^{\text {th }} 2000$, the sample of the period prior to 2007 is not utilized because it has not enough stocks to build portfolios.

To compute the past 13-week returns on individual stocks and to measure returns on the momentum portfolios which are held up to 13 weeks, we require all selected stocks to have return history of at least 26 weeks. Thus, stocks listed after January $1^{\text {st }} 2012$ are deleted from our sample. In addition, for some stocks that had been traded in the Hanoi Stock Exchange (HNX) before being moved to the HOSE, only the data for the period of being traded in the HOSE are utilized ${ }^{5}$. The sample also excludes some stocks that had been traded in the HOSE before being moved to the HNX as they were small firms and did not meet the HOSE's minimum capital regulation for listing ${ }^{6}$. Furthermore, to avoid the effect of extremely small and/ or illiquid stocks, we treat them as follows. First, for small stocks that have prices below VND10,000 ${ }^{7}$ in any single week, their returns in that week is treated as missing. Second, in a week that a stock is not traded, its return is also treated as missing. After handling the small and illiquid stocks, we again screen out stocks with the requirement of having at least

\footnotetext{
${ }^{5}$ We do not use the data in the HNX because of the differences in trading mechanisms in the two exchanges. While the HOSE employs two trading methods: a call auction to determine opening and closing prices, and a continuous order matching, the HNX applies only a continuous order matching method. Also, the regulated daily price limit in the HOSE is (+/-) 5 percent, while that in the HNX is (+/-) 7 percent. Therefore, the inclusion of data from the HNX may cause bias. 6 According to Document No.163/UBCK-PTTT issued by the State Security Commission of Vietnam on 10 February 2009, by August 2009 (retrieved from http://www.vinanet.com.vn/uy-ban-chung-khoan-nha-nuoc/300/cqbh.xhtml ) those firms who are being listed on the HOSE but cannot meet the minimum capital of 80 billion Vietnamese Dong (VND) have to move to the HSX which applies a minimum capital of 10 billion VND.

${ }^{7}$ In Vietnam all stocks have a face value of ten thousand VND.
} 
26-week returns. Finally, we have a sample with the number of stocks ranging from 67 (in beginning of 2007) to 267 (at the end of 2011).

As the prices have already been adjusted for dividend payments and stock splits, the simple weekly return on each security is calculated - using Wednesday-Wednesday closing prices to avoid the weekend effects. The choice of a weekly sampling interval is to gain a large number of observations while lessening the biases arising from the daily price limit ${ }^{8}$. Instead of using continuously compounded returns, we choose simple returns as the simple return on a portfolio is equal to the weighted average of its component stocks' simple returns. This characteristic does not work for the continuously compounded returns.

The market index, the VN-Index, calculated as the capitalization-weighted average of all stocks listed on the HOSE is employed as a proxy for the market portfolio. The weekly return of VN-Index calculated based on Wednesday-Wednesday closing indices is applied as a proxy of the market return. An equivalent weekly rate of the five year-Treasury bond with an assumption that there are 52 weeks in a year is adopted as a proxy for the risk-free rate ${ }^{9}$.

\section{Methodology}

We employ the methodology initiated by JT (1993) but with weekly returns to examine the profitability of momentum strategies. We rank all stocks in week $t$ from the lowest to the highest on the basis of their average returns over past $K$ weeks. The stocks in the highest quintile are named "winners" and those in the lowest quintile "losers". Winner and loser portfolios are formed by allocating an equal weight across all component stocks. A portfolio that buys the winner portfolio and sells the loser portfolio is formed at week $t$ and then held for $J$ weeks (from week $t$ to week $t+J)^{10}$. This is regarded as a winner-minus-loser (WML) portfolio. We call profit on the WML portfolio, because this is a zero-cost strategy, return is not determined.

A momentum strategy is formed at week $t$ and held for $J$ weeks, thus, $J$ time series of raw profits on the WML portfolios are created. $R_{k, t}^{W M L}(k=1, \ldots, J)$ are the raw profits on the WML portfolios that are formed $k$ weeks ago. Following literature, in order to increase the power of our tests, overlapping profits in a given calendar week are examined. At week $t$, there are $J$ WML portfolios - one formed in week $t-1$, one formed in week $t-2$, and so on. With an assumption of no transaction cost, the overlapping profit in calendar week $t$ can be calculated as an equally weighted average of the $J$ overlapping portfolios' profits in that week:

$$
O R_{J, t}^{W M L}=\frac{1}{J} \sum_{k=1}^{J} R_{k, t}^{W M L}
$$

\footnotetext{
8 The regular daily price limit of the HOSE is (+/-) 5 percent.

${ }^{9}$ Since the data on the secondary market T-bonds' yields are not available, we use the primary market yields by regarding the minimum among accepted yields of bond auctions - conducted within a month as the rate of that month. For any month in which no auction is implemented or succeeded, the rate of the previous month is applied alternatively. We choose the five year-T bond's yield as this bond is the most - frequently issued. The data are collected from the website of HNX (http://bond.hnx.vn )

${ }_{10}$ Although in Vietnam short sales are prohibited, due to the loose management of the Vietnamese securities agency, brokers can short their customers' securities. For example, according to Hoang Loc, "Co hay khong hoi ban khong co phieu? (“Are there stock- short selling groups?”) VnEconomy News on 10 September 2012 (retrieved from http://vneconomy.vn/2012090911541106P0C7/co-hay-khong-hoi-ban-khong-co-phieu.htm ); Hai Dang, "Nhieu chieu ban khong chung khoan” ("Many ways to short stocks"), Tuoi Tre News on 17 October 2012 (retrieved from http://tuoitre.vn/kinh-te/516266/nhieu-chieu-ban-khong-chung-khoan.html), stock short sales are prevalent in Vietnam. Thus, the prohibition of short sales is not cause for concern.
} 


\section{Macrothink}

The overlapping returns on winner and loser portfolios in a given calendar week $t$ can be calculated similarly.

The average of overlapping profit on the WML portfolio is employed as a metric to test the momentum of the market. If the average profit is significantly positive, the momentum occurs, otherwise, it does not exist. As the number of observations in our sample is limited, the profits on WML portfolios which are formed based on stock average returns over past one, two, four, eight and thirteen weeks ( $K=1,2,4,8$ and 13) and held for the periods of one, two, four, eight and thirteen weeks ( $J=1,2,4,8$ and 13) are tested.

\section{Empirical results}

\subsection{Evidence on the momentum effect}

Table 1 presents the average raw returns and profits on the winner, loser and WML portfolios which select stocks based on their average returns over past $K$ weeks and hold them for $J$ weeks ( $K=1,2,4,8$ and 13, $J=1,2,4,8$ and 13).

The results show that the profits on the WML portfolios with $K=1$ are significantly positive over all holding periods $(J)$, while those on the WML portfolios with other intervals $(K)$ are significantly positive over one, two or three holding periods. In addition, for each interval $(K)$ the profit tends to fall for longer holding period $(J)$, which is similar to the findings of Rouwenhorst (1998). The portfolio with $K=1$ and $J=1$ earns the highest profit of 0.83 percent per week. 
Table 1. Returns and profits on winner, loser and winner-minus-loser portfolios

\begin{tabular}{|c|c|c|c|c|c|c|c|}
\hline$K$ & $J$ & $\mathbf{0}$ & 1 & 2 & 4 & 8 & 13 \\
\hline \multirow[t]{6}{*}{1} & Winners & $0.0833^{* * *}$ & 0.0054 & 0.0038 & 0.0026 & 0.0017 & 0.0014 \\
\hline & & (21.11) & (1.35) & $(0.93)$ & $(0.62)$ & $(0.41)$ & $(0.32)$ \\
\hline & Losers & $-0.0707 * * *$ & -0.0029 & -0.002 & -0.0004 & -0.0002 & 0.0000 \\
\hline & & $(-24.92)$ & $(-0.83)$ & $(-0.54)$ & $(-0.09)$ & $(-0.06)$ & $(0.00)$ \\
\hline & WML & $0.1540^{* * *}$ & $0.0083^{* * *}$ & $0.0058 * * *$ & $0.0030 *$ & $0.0020 *$ & $0.0014 *$ \\
\hline & & $(57.11)$ & (3.22) & (2.69) & (1.76) & (1.70) & (1.70) \\
\hline \multirow[t]{6}{*}{2} & Winners & $0.0584^{* * *}$ & 0.0040 & 0.0033 & 0.0028 & 0.0020 & 0.0016 \\
\hline & & (14.73) & (1.03) & (0.83) & $(0.67)$ & $(0.47)$ & (0.38) \\
\hline & Losers & $-0.0488 * * *$ & -0.0022 & -0.0014 & -0.0003 & -0.0004 & -0.000 \\
\hline & & $(-16.36)$ & $(-0.61)$ & $(-0.35)$ & $(-0.06)$ & $(-0.09)$ & $(-0.00)$ \\
\hline & WML & $0.1073 * * *$ & $0.0062 * *$ & $0.0047 * *$ & 0.0031 & 0.0024 & 0.0016 \\
\hline & & $(40.69)$ & (2.33) & (2.00) & (1.60) & (1.60) & (1.56) \\
\hline \multirow[t]{6}{*}{4} & Winners & $0.0408 * * *$ & 0.0039 & 0.0036 & 0.0032 & 0.0020 & 0.0017 \\
\hline & & (10.91) & (1.02) & (0.93) & $(0.77)$ & $(0.47)$ & $(0.40)$ \\
\hline & Losers & $-0.0341 * * *$ & -0.0006 & -0.0007 & -0.0005 & -0.0001 & 0.00005 \\
\hline & & $(-11.40)$ & $(-0.16)$ & $(-0.16)$ & $(-0.13)$ & $(-0.03)$ & $(0.01)$ \\
\hline & WML & $0.0749 * * *$ & $0.0044 *$ & $0.0043^{*}$ & $0.0037 *$ & 0.0021 & 0.0016 \\
\hline & & (32.14) & (1.75) & (1.79) & (1.77) & (1.18) & (1.23) \\
\hline \multirow[t]{6}{*}{8} & Winners & $0.0289 * * *$ & 0.0037 & 0.0032 & 0.0025 & 0.0020 & 0.0014 \\
\hline & & $(8.01)$ & (0.99) & $(0.83)$ & $(0.61)$ & $(0.46)$ & $(0.33)$ \\
\hline & Losers & $-0.0249 * * *$ & -0.0010 & -0.0006 & -0.0004 & -0.0001 & 0.0005 \\
\hline & & $(-7.98)$ & $(-0.27)$ & $(-0.14)$ & $(-0.10)$ & $(-0.03)$ & $(0.10)$ \\
\hline & WML & $0.0538 * * *$ & $0.0047^{*}$ & 0.0040 & 0.0030 & 0.0021 & 0.0009 \\
\hline & & (23.68) & (1.88) & (1.54) & (1.23) & (1.01) & $(0.52)$ \\
\hline \multirow[t]{6}{*}{13} & Winners & $0.0224 * * *$ & 0.0040 & 0.0033 & 0.0025 & 0.0017 & 0.0011 \\
\hline & & (6.38) & $(1.08)$ & $(0.86)$ & $(0.62)$ & $(0.40)$ & $(0.28)$ \\
\hline & Losers & $-0.0203 * * *$ & -0.0013 & -0.0011 & -0.0006 & 0.00005 & 0.0005 \\
\hline & & $(-6.30)$ & $(-0.35)$ & $(-0.26)$ & $(-0.14)$ & $(0.01)$ & $(0.11)$ \\
\hline & WML & $0.0427 * * *$ & $0.0053^{* *}$ & $0.0044^{*}$ & 0.0031 & 0.0016 & 0.0006 \\
\hline & & (19.80) & (2.13) & (1.70) & (1.18) & $(0.68)$ & $(0.32)$ \\
\hline
\end{tabular}

Note: t-statistics are calculated using Newey-West standard errors and setting the number of lags equal to the number of overlapping weeks in each calendar week. $\left({ }^{* * *}\right),(* *),\left(^{*}\right)$ indicate significance at the 1\%, 5\% and $10 \%$ level, respectively. $\quad$ t-statistics are presented in parentheses.

Taking a look at the profits on the WML portfolios with $K=1,2,4,8$ and $13, J=1$, we find that the profits are still significant for sorting intervals longer than one week, but the portfolio with $K=1$ has a higher and less risky ${ }^{11}$ profit than the others. We have similar results with $J=2,8$ and 13. These findings imply that one-week returns provide more substantial

\footnotetext{
${ }^{11}$ The standard deviation of profit on the portfolio with $K=1$ is lower than those of the others. The information on the standard deviations of winners, loser and WML portfolios' returns is available upon request.
} 
information than longer-horizon returns in predicting future returns. For $J=4$, the portfolio with $K=4$ gains a larger profit ( 0.37 percent per week) but suffers from larger risk (standard deviation of 3 percent per week) than the portfolio with $K=1$, of which the profit and standard deviation are 0.30 percent and 2.11 percent per week, respectively. Put differently, the portfolio with $K=4$ has a 23 percent higher gain but bears 42 percent larger risk than the one with $K=1$. This means that the latter is better than the former, confirming the ability of one-week returns in predicting future returns.

From a practical point of view, it is important to examine the profitability of the momentum strategies after considering transaction costs. In the Vietnamese stock market, transaction costs range from 0.15 percent to 0.35 percent of trading value and decrease for larger trading value $^{12}$. Since momentum is considered as an arbitrage opportunity which is commonly realized by institutional investors with huge trading value, it is plausible to impose the lowest trading cost of 0.15 percent on the momentum strategies. Considering the strategy with $J=1$, the transaction cost is imposed twice on each long and short position at the portfolio formation and disposal. Furthermore, the momentum profit is the difference between returns on winner and loser portfolios, thus can be seen as return per dollar invested in the long position. Consequently, for the strategy with $J=1$, four times of the transaction cost should be cut down from its profit. For the strategy with $J=2$, since the profit is determined as the overlapping average profit on two WML portfolios at a calendar week, the transaction cost is charged four times to each position during two weeks. This means that the transaction cost is imposed twice per week on each long and short position. Hence, for the strategy with $J=2$, four times of the transaction cost should be deducted from its weekly profit. Similarly, for the strategies with $J=4,8$ and 13, four times of the transaction cost should be subtracted from their weekly profit. After accounting for a transaction cost of 0.15 percent, only profits on the two strategies with $K=1,2$ and $J=1$ still exist, whereas the profits on the remaining strategies vanish absolutely.

Table 1 also reports the average returns on winners and losers separately. The winner and loser returns are insignificant for all couples of $K$ and $J$, raising a concern over their significance in the sorting week, that is, whether the momentum strategies are based on significant information. The first column indicates that in the sorting week $(J=0)$, the returns on winners are significantly positive and decrease as the ranking interval is longer, while the returns on losers are significantly negative and their absolute values decrease for longer ranking intervals. This means that the momentum strategies are built on significant information. Furthermore, the decrease in the absolute values of the t-statistics for longer sorting intervals confirms our previous findings that the backward interval of one week provides more substantial information than longer sorting horizons.

The extremely high returns of winners in the sorting week $(J=0)$ in comparison with their low and insignificant returns in the following weeks raise a concern whether the high returns are driven by some special corporate events such as stock issues. Since the list of winners and losers varies from week to week, it is difficult to examine the relationship between stock

12 According to the trading fee tables of some big securities companies such as HSC, SSI, VCBS, ACBS as in October 2012. The lowest trading cost ( 0.15 percent) is provided by HSC and VCBS for the trading value of more than one billion VND (equivalently, USD 50,000). 
returns and stock issues for all stocks within this paper. Thus, we carry out a rough test on some specific stocks of high and low frequency of being winners (losers). We sort stocks by their frequency of being winners (losers), select top ten high- and low-frequency stocks and observe the events of stock issue during our sample period. The findings uncover that the high returns are not likely to be driven by the stock issuances ${ }^{13}$. For example, a mining stock, named KSH had 57 times of being a winner in its 163 observations for the period of three and a half year, but did not have any stock issue during the period. However, a real estate stock, namely PPI had two times of stock issues but suffered 22 times of being a loser relative to its 61 observations in more than two years. Thus, the correlation between the high returns in sorting weeks and the stock issuances is unlikely to exist. This test also reveals that eight of the top ten-high frequency stocks being winners have higher average returns than the market average return, whereas seven of the top ten -low frequency stocks being winners have lower average returns. This means that winners can be divided into two groups: "clear winners"- the stocks with high persistence of their returns and "noisy winners"- the stocks with low persistence of their returns. For the losers, all top ten-high frequency stocks being losers have lower average returns than the average market return, whereas nine of top ten-low frequency stocks being losers have higher average returns. Put differently, two kinds of clear and noisy losers are also found. Moreover, the correlation between these two frequencies is 34.59 percent, indicating that the probability of a winner becoming a loser and vice versa is extremely high. The low persistence of winners and losers is reaffirmed by the results in Table 2, which provides information on the conditional probability of a stock belonging to group $i$ at week $t$, given the knowledge that it has been already sorted in group $j$ at week $t-1$.

Table 2. Transition matrix

\begin{tabular}{|c|c|c|c|c|c|c|}
\hline & \multicolumn{6}{|c|}{$S=i, t$} \\
\hline \multirow{6}{*}{$S=j, t-1$} & & 1 & 2 & 3 & 4 & 5 \\
\hline & 1 & 0.2135 & 0.1851 & 0.1805 & 0.1971 & 0.2238 \\
\hline & 2 & 0.1669 & 0.2153 & 0.221 & 0.2201 & 0.1768 \\
\hline & 3 & 0.1671 & 0.2078 & 0.2275 & 0.2201 & 0.1776 \\
\hline & 4 & 0.1838 & 0.2153 & 0.2079 & 0.2037 & 0.1894 \\
\hline & 5 & 0.2437 & 0.1817 & 0.1631 & 0.1708 & 0.2408 \\
\hline
\end{tabular}

Note: For each week from January 2007 to June 2012, stocks are ranked from the highest to the lowest based on their previous one week return $(K=1)$ and then divided into five groups. Group 1 includes the lowest-quintile stocks, i.e. the losers; group 5 consists of the highest-quintile ones, i.e. the winners and the same rules for others. The conditional probability of a stock belonging to group $i$ at week $t$, given the knowledge that it has been already sorted in group $j$ at week $t-1$, i.e., Prob ( $S=i$, $t \mid S=j, t-1)$ is presented in the table.

\footnotetext{
${ }^{13}$ The detailed results are available upon request.
} 
The results indicate that only 24.08 percent of winners continue being winners and 21.35 percent of losers continue being losers in the following week. The probability of a winner falling in other groups for the subsequent week is 75.02 percent, including a 24.37 percent chance of dropping into losers. The probability of a loser moving to other groups in the subsequent week is 78.65 percent, including a 22.38 percent chance of becoming a winner. The high volatility of stock returns confirms the existence of noisy winners and losers.

An additional question is why the insignificant returns of winners and losers produce significant momentum profits. The average standard deviations of returns or profits on the winner, loser and WML portfolios for all couples of $K$ and $J$ are 0.0536, 0.0552 and 0.0296, respectively. The average correlation between the winner and loser returns is around 0.85 . As the WML portfolios are built by buying the winners and selling the losers, the highly positive correlation between winner and loser returns reduces the standard deviation of the WML profits, making the momentum profits significant in some periods. Put differently, the findings confirm the portfolio diversification effect: high correlation between long and short positions produce less variance of the WML profits. Nevertheless, the risk of WML profits still exists, which should be accounted for in the next section.

JT (1993) argue that in order to avoid some of the bid-ask spread, price pressure and lagged reaction effects, a second set of strategies that skip one week between the portfolio formation and the holding periods should be examined. Since we use closing prices determined by call-auctions, the problem of bid-ask spread is not a concern.

In a nutshell, the evidence asserts that momentum occurs in the Vietnamese stock market for some sorting and holding periods. After being controlled for transaction costs, only two strategies with $K=1,2$ and $J=1$ earn significantly positive profits. The results also indicate that one-week returns provide more substantial information than longer-horizon returns in predicting future returns. Furthermore, the winner and loser returns are lowly persistent and highly volatile, but their strong correlation creates significant momentum profits.

\subsection{Momentum profits within size-and pre-or post Lehman shock-subsamples}

JT (1993) argue that if the momentum profits are driven by the cross-sectional dispersion in expected returns, the size-subsamples will earn lower profits than the full sample due to the less difference of expected returns within size-subsamples. Additionally, if the profits are factor-related, the small-sized subsample- which consists of less actively traded stocks is likely to yield a higher profit than the large-sized subsample.

In our sample, the average market capitalization of winners and losers shows that the winners contain large firms, while the losers include small firms ${ }^{14}$, which is different from JT(1993)'s result that the highest and lowest past return-portfolios consist of small stocks. This implies that the momentum may be limited to any particular subsample of stocks. Thus, at the beginning of each year, we classify stocks into three categories of small, medium and large sizes based on their market capitalization at the previous year-end ${ }^{15}$. The profits on the WML

\footnotetext{
${ }^{14}$ The average market capitalization of winners and losers is 2,620 billion VND and 2,280 billion VND, respectively, while that of the entire sample is 2,540 billion VND.

${ }^{15}$ Market capitalization of each firm at the year-end is calculated as a product of the market price of its common stock and
} 
portfolio built from the three categories are examined to clarify whether they are due to either the difference in expected returns or the positive serial correlation in factor returns.

Fama (1970, 1991) asserts that anomalies should be tested in the context of a pricing model as they may be compensation for risk. Additionally, our previous section asserts that although being zero-cost portfolios, the momentum strategies are still risky. Thus, we employ two commonly used models- the CAPM and the Fama-French three factor model ${ }^{16}$ to account for risk.

Furthermore, Chordia and Shivakumar (2002) find relationship between momentum profits and business cycle; JT (2011) report negative momentum profits in 2008 and 2009 when the market severely declined; Chui et al. (2000) show insignificant momentum profits in the Asian markets for the post-crisis period. Our sample includes a severe market decline period since the beginning of 2008. From its high level of 800 points at the beginning of 2008, VN Index has fell to about 400 points in June, recovered to around 500 points at the beginning of September, but since the Lehmann shock it has again slumped to the lowest level of 234 points in February, 2009, and then has been sluggish around 400 points to the end of the sample period. Besides, during the period from 27/3/2008 to 18/8/2008, to prevent market declines, the State Securities Commission of Vietnam applied temporary daily price limits varying from (+/-)1 percent to (+/-) 3 percent instead of the regular regulation of (+/-) 5 percent. This sample period should be removed from our sample to prevent bias arising due to the administrative intervention. Hence, we divide our sample into two periods: before the Lehmann shock (from January 2007 to March 2008) and after the Lehmann shock (from September 2008 to June 2012) to examine whether the momentum effect is limited to any particular period.

As reported earlier, the strategy with $K=1$ and $J=1$ yields the highest profit, thus for brevity, the profit of this strategy constructed within size- and pre- and post- Lehmann shock subsamples is further examined. The results are presented in Table 3.

Observing the momentum profits by periods, we find that the raw and the risk-adjusted profits in the first period are strongly and significantly positive, while those in the second period are insignificant. This means that the momentum is confined to the period prior to the Lehmann shock. Our statistics ${ }^{17}$ shows that the standard deviations and the correlation of winner and looser returns in the first period are not very different from the corresponding statistics in the second period, while the difference between winner and loser returns in the first period is rather higher than that in the second period. Indeed, large difference between winner and looser mean returns makes momentum significant in the first period and small difference drives the momentum insignificant in the second period.

\footnotetext{
the number of outstanding stocks at that time.

${ }^{16}$ We follow Fama and French (1996) to build the SMB and HML portfolios.

17 The means, standard deviations and the correlation of winner and loser returns in the first period is $0.78 \%$, $-0.82 \%, 6.4 \%$ (standard deviation), $5.7 \%$ (standard deviation) per week and 0.80 , while those for the second period are $0.25 \%, 0.14 \%, 5.4 \%$ (standard deviation), 5.1\%( standard deviation) per week and 0.83 .
} 
Table 3. Momentum within size-, pre- and post-the Lehmann shock subsamples

\begin{tabular}{llllll}
\hline Periods & & All & Small & Medium & Large \\
\hline Whole period & Raw & $0.0083^{* * *}$ & 0.0026 & 0.0030 & $0.0094^{* * *}$ \\
1/2007-6/2012 & & $(3.22)$ & $(0.83)$ & $(1.16)$ & $(3.24)$ \\
& \multirow{2}{*}{ CAPM alpha } & $0.0086^{* * *}$ & 0.0032 & 0.0034 & $0.0097^{* * *}$ \\
& & $(3.25)$ & $(1.04)$ & $(1.32)$ & $(3.34)$ \\
& FF alpha & $0.0084^{* * *}$ & 0.0028 & 0.0032 & $0.0098^{* * *}$ \\
& & $(3.20)$ & $(0.94)$ & $(1.27)$ & $(3.32)$ \\
\hline First period & Raw & $0.0161^{* * *}$ & $0.0156^{* *}$ & 0.0057 & $0.0154^{* *}$ \\
$1 / 2007-3 / 2008$ & & $(2.77)$ & $(2.24)$ & $(1.12)$ & $(2.40)$ \\
& \multirow{2}{*}{ CAPM alpha } & $0.0171^{* * *}$ & $0.0171^{* *}$ & 0.0061 & $0.0168^{* *}$ \\
& & $(2.82)$ & $(2.54)$ & $(1.16)$ & $(2.55)$ \\
& \multirow{2}{*}{ FF alpha } & $0.0154^{* *}$ & $0.0148^{*}$ & 0.0045 & $0.0163^{* *}$ \\
Second period & Raw & $(2.54)$ & $(2.06)$ & $(0.84)$ & $(2.40)$ \\
9/2008-6/2012 & & 0.0007 & -0.0054 & -0.0031 & 0.0021 \\
& \multirow{2}{*}{ CAPM alpha } & $(0.30)$ & $(-1.59)$ & $(-1.33)$ & $(0.76)$ \\
& & 0.0006 & -0.0050 & -0.0029 & 0.0022 \\
& FF alpha & $(0.28)$ & $(-1.50)$ & $(-1.25)$ & $(0.78)$ \\
& & 0.0005 & -0.0052 & -0.0029 & 0.0023 \\
& $(0.21)$ & $(-1.58)$ & $(-1.20)$ & $(0.78)$ \\
\hline
\end{tabular}

Note: $t$-statistics are calculated using Newey-West standard errors to test the null hypothesis that the profit or alphas are equal to zero. $\left({ }^{* *}\right),\left({ }^{* *}\right),\left(^{*}\right)$ indicate significance at the $1 \%, 5 \%$ and $10 \%$ level, respectively. $\quad t$-statistics are presented in parentheses.

Looking at profits by sizes, we find that for the first period, the small and the large-sized subsamples have a little bit lower raw profits than the full sample. Additionally, the small-sized subsample gains a little bit higher profit than the large-sized one. These results do not strongly support the argument by JT (1993) that momentum may be due to the dispersion in expected returns or the positive serial correlation in factor returns. Furthermore, the risk-adjusted profits from the small and the large-sized subsamples are statistically significant. This means that momentum is limited to the small and large-sized subsamples and cannot be regarded as the compensation for risk. Hence, it can be considered as delayed price reactions to information, as mentioned in JT (1993). For the second period, the raw and the risk-adjusted profits from all size-subsamples are not significant, which is in accordance with the previous finding on the absence of momentum during this period.

\subsection{Performance of momentum profits in the post-holding period}

In this section we analyze the profits in longer horizons following the holding period to examine whether the momentum is driven by either the under-reaction or the over-reaction hypothesis. Due to the limitation of observation number, we focus on the profits up to six months or 26 weeks following the formation week. Additionally, the profit on the strategy with $K=1$ and $J=1$ is further examined. 


\section{Macrothink

As described earlier, 26 time series of raw profits on the WML portfolios that are formed $k$ weeks ago $(k=1, \ldots, 26)$ are created. Following Cooper et al. (2004), we regress these 26 time series of raw profits against a constant and the appropriate factors.

$$
R_{k t}=\alpha+\sum_{i} \beta_{i k} f_{i t}+\varepsilon
$$

Then, the risk-adjusted profits are calculated as:

$$
R_{k t}^{a d j}=R_{k t}-\sum_{i} \hat{\beta}_{i k} f_{i t}
$$

Where $R_{k t}$ is the time series of raw profits on the WML portfolio that is formed $k$ weeks ago. $f_{i t}$ is the realization of factor $i$ in week $t$. $\hat{\beta}_{i k}$ is the estimated loadings of the time series of raw profit on the factors. The excess return of the market index over the risk free rate is used as the unique factor for the CAPM-adjusted profit, and the two more factors, SMB and HML, are served for the Fama-French-adjusted profit.

The weekly average raw or risk-adjusted profits between week $k_{1}$ and $k_{2}$, following the formation week are calculated:

$$
A R_{k_{1}, k_{2}}=\sum_{k=k_{1}}^{k_{2}} R_{k, t+k}^{*} /\left(k_{2}-k_{1}+1\right)
$$

Where $A R_{k_{1}, k_{2}}$ is the average weekly profit between week $k_{1}$ and $k_{2}, R^{*}$ is either the raw or the risk-adjusted profit. Table 4 demonstrates the weekly average profits over the first month $\left(k_{1}=2, k_{2}=5\right)$, second month $\left(k_{1}=6, k_{2}=9\right)$, third month $\left(k_{1}=10, k_{2}=13\right)$ and the following three months $\left(k_{1}=14, k_{2}=26\right)$ after the holding period.

Table 4 shows that for the whole and the first periods, after reaching a significantly positive rate in week 1, the raw and the risk-adjusted profits become insignificant in the subsequent months. In the second period, the raw and risk-adjusted profits are insignificant in week 1 and in all following months, confirming the absence of momentum. 
Table 4. Average weekly profit in the post holding periods

\begin{tabular}{|c|c|c|c|c|c|c|}
\hline & Week 0 & Week 1 & Week 2-5 & Week 6-9 & Week 10-13 & Week 14-26 \\
\hline \multicolumn{7}{|c|}{ Whole period (1/2007-6/2012) } \\
\hline \multirow[t]{2}{*}{ Raw profit } & $0.1540 * * *$ & $0.0083 * * *$ & 0.0009 & 0.0004 & 0.0007 & -0.0006 \\
\hline & $(57.11)$ & $(3.22)$ & $(0.80)$ & $(0.40)$ & $(0.65)$ & $(-1.00)$ \\
\hline \multirow[t]{2}{*}{ CAPM alpha } & $0.1547 * * *$ & $0.0086 * * *$ & 0.0009 & 0.0004 & 0.00067 & -0.0006 \\
\hline & $(59.56)$ & $(3.25)$ & $(0.80)$ & $(0.41)$ & $(0.60)$ & $(-1.11)$ \\
\hline Fama-French & $0.1542 * * *$ & $0.0084 * * *$ & 0.0009 & 0.0007 & 0.00087 & -0.00065 \\
\hline alpha & $(62.24)$ & $(3.20)$ & $(0.78)$ & $(0.65)$ & $(0.86)$ & $(-1.30)$ \\
\hline \multicolumn{7}{|c|}{ First period (1/2007-3/2008) } \\
\hline \multirow[t]{2}{*}{ Raw profit } & $0.1562 * * *$ & $0.0161^{* * *}$ & 0.0023 & 0.0017 & 0.0014 & -0.0013 \\
\hline & $(22.74)$ & $(2.77)$ & $(0.91)$ & $(0.49)$ & $(0.37)$ & $(-1.10)$ \\
\hline \multirow[t]{2}{*}{ CAPM alpha } & $0.1586 * * *$ & $0.0171^{* * *}$ & 0.0026 & 0.0021 & 0.0016 & -0.0014 \\
\hline & $(24.61)$ & $(2.82)$ & $(1.07)$ & $(0.66)$ & $(0.43)$ & $(-1.19)$ \\
\hline \multirow{2}{*}{$\begin{array}{l}\text { Fama-French } \\
\text { alpha }\end{array}$} & $0.1556 * * *$ & $0.0154 * * *$ & 0.0025 & 0.0037 & 0.0038 & -0.0011 \\
\hline & $(25.75)$ & $(2.54)$ & $(1.01)$ & $(1.42)$ & $(1.40)$ & $(-0.72)$ \\
\hline \multicolumn{7}{|c|}{ Second period (9/2008-6/2012) } \\
\hline \multirow[t]{2}{*}{ Raw profit } & $0.1554 * * *$ & 0.0007 & -0.0011 & 0.0003 & 0.0008 & -0.0006 \\
\hline & (58.19) & $(0.30)$ & $(-0.94)$ & $(0.37)$ & $(0.81)$ & $(-0.86)$ \\
\hline \multirow[t]{2}{*}{ CAPM alpha } & $0.1558 * * *$ & 0.0006 & -0.0011 & 0.0003 & 0.0007 & -0.0007 \\
\hline & $(58.97)$ & $(0.28)$ & $(-0.95)$ & $(0.34)$ & $(0.77)$ & $(-0.90)$ \\
\hline Fama-French & $0.1559 * * *$ & 0.0005 & -0.0012 & 0.0000 & 0.0006 & -0.0009 \\
\hline alpha & $(63.40)$ & $(0.21)$ & $(-1.10)$ & $(0.02)$ & $(0.65)$ & $(-1.35)$ \\
\hline
\end{tabular}

Note: $\left({ }^{* * *}\right),\left({ }^{* *}\right),\left({ }^{*}\right)$ indicate significance at the $1 \%, 5 \%$ and $10 \%$ level, respectively. $t$-statistics are presented in parentheses.

The results in Table 3 indicate that momentum is confined to the period prior to the Lehmann shock, that is, it seems to be related to market states. Hence, we look closer at the relationship between momentum and market states. Due to the limitation of our observation number, we define market state based on lagged eight-week market returns. The state is regarded as "UP" if the lagged market-return is non-negative, and as "DOWN" if the lagged market-return is negative.

Following Cooper et al. (2004), we regress the time-series of weekly average raw or risk adjusted profits on an UP dummy variable and a DOWN dummy variable, with no intercept to calculate the profit following each state. The results are presented in Table 5.

Panel A reveals that for the whole period, the raw and risk-adjusted profits following UP states are significantly and strongly positive in week 1, preserve their significance in week 2-5, and become insignificant in longer horizons. On the other hand, following DOWN states, the raw and the CAPM-adjusted profits except for the raw one in week 10-13 are not statistically significant in week 1 and in the subsequent months. After being controlled for the 
three factors, the profit is weakly significant in week 1 and insignificant in the subsequent months.

Table 5. Momentum and market states

\begin{tabular}{|c|c|c|c|c|c|c|}
\hline & Week 0 & Week 1 & Week 2-5 & Week 6-9 & Week 10-13 & Week 14-26 \\
\hline \multicolumn{7}{|c|}{ Panel A: Whole period (1/2007-6/2012) } \\
\hline \multicolumn{7}{|c|}{ Average weekly profits following UP markets } \\
\hline \multirow[t]{2}{*}{ Raw profit } & $0.1715 * * *$ & $0.0135^{* * *}$ & $0.0030 * *$ & -0.0002 & -0.0013 & -0.0008 \\
\hline & $(45.49)$ & $(4.13)$ & $(2.20)$ & $(-0.15)$ & $(-0.88)$ & $(-1.12)$ \\
\hline \multirow[t]{2}{*}{ CAPM alpha } & $0.1711^{* * *}$ & $0.0133 * * *$ & $0.0031^{* *}$ & -0.0004 & -0.0010 & -0.0006 \\
\hline & $(47.13)$ & $(4.12)$ & $(2.30)$ & $(-0.33)$ & $(-0.67)$ & $(-0.81)$ \\
\hline \multirow{2}{*}{$\begin{array}{l}\text { Fama-French } \\
\text { alpha }\end{array}$} & $0.1688 * * *$ & $0.0127 * * *$ & $0.0029 * *$ & 0.0007 & -0.00002 & -0.0011 \\
\hline & $(48.51)$ & $(3.94)$ & $(2.22)$ & $(0.59)$ & $(-0.02)$ & $(-1.56)$ \\
\hline \multicolumn{7}{|c|}{ Average weekly profits following DOWN markets } \\
\hline \multirow[t]{2}{*}{ Raw profit } & $0.1397 * * *$ & 0.0041 & -0.0007 & 0.0009 & $0.0024^{*}$ & -0.0004 \\
\hline & $(40.99)$ & $(1.40)$ & $(-0.59)$ & $(0.79)$ & $(1.80)$ & $(-0.62)$ \\
\hline \multirow[t]{2}{*}{ CAPM alpha } & $0.1413^{* * *}$ & 0.0047 & -0.0008 & 0.0012 & 0.0020 & -0.0007 \\
\hline & $(43.05)$ & $(1.59)$ & $(-0.66)$ & $(0.98)$ & $(1.54)$ & $(-1.07)$ \\
\hline Fama-French & $0.1424 * * *$ & $0.0049 *$ & -0.0007 & 0.0007 & 0.0016 & -0.0003 \\
\hline alpha & $(45.27)$ & $(1.69)$ & $(-0.61)$ & $(0.57)$ & $(1.29)$ & $(-0.47)$ \\
\hline \multicolumn{7}{|c|}{ Panel B: First period (1/2007-3/2008) } \\
\hline \multicolumn{7}{|c|}{ Average weekly profits following UP markets } \\
\hline \multirow[t]{2}{*}{ Raw profit } & $0.1914 * * *$ & $0.0257 * * *$ & $0.0071 * *$ & 0.0034 & -0.0027 & 0.0000 \\
\hline & $(22.66)$ & $(3.55)$ & $(2.19)$ & $(0.87)$ & $(-0.54)$ & $(0.02)$ \\
\hline \multirow[t]{2}{*}{ CAPM alpha } & $0.1899 * * *$ & $0.0247 * * *$ & $0.007 * *$ & 0.0023 & -0.0025 & -0.0002 \\
\hline & $(23.53)$ & $(3.48)$ & $(2.23)$ & $(0.61)$ & $(-0.52)$ & $(-0.09)$ \\
\hline \multirow{2}{*}{$\begin{array}{l}\text { Fama-French } \\
\text { alpha }\end{array}$} & $0.1849 * * *$ & $0.0224 * * *$ & $0.0063^{* *}$ & $0.0067 * *$ & 0.0034 & $-0.0039 *$ \\
\hline & $(24.50)$ & $(3.24)$ & $(2.12)$ & $(2.02)$ & $(0.80)$ & $(-1.88)$ \\
\hline \multicolumn{7}{|c|}{ Average weekly profits following DOWN markets } \\
\hline \multirow[t]{2}{*}{ Raw profit } & $0.1280^{* * *}$ & 0.0085 & -0.0015 & 0.0002 & 0.0046 & -0.0024 \\
\hline & $(16.95)$ & $(1.31)$ & $(-0.51)$ & $(0.07)$ & $(1.05)$ & $(-1.29)$ \\
\hline \multirow[t]{2}{*}{ CAPM alpha } & $0.1341 * * *$ & $0.0110^{*}$ & -0.0009 & 0.0019 & 0.0048 & -0.0023 \\
\hline & $(18.66)$ & $(1.73)$ & $(-0.31)$ & $(0.58)$ & $(1.11)$ & $(-1.27)$ \\
\hline \multirow{2}{*}{$\begin{array}{l}\text { Fama-French } \\
\text { alpha }\end{array}$} & $0.1322 * * *$ & 0.0099 & -0.0006 & 0.0013 & 0.0042 & 0.0011 \\
\hline & $(19.59)$ & $(1.60)$ & $(-0.21)$ & $(0.44)$ & $(1.11)$ & $(0.57)$ \\
\hline \multicolumn{7}{|c|}{ Panel C: Second period (9/2008-6/2012) } \\
\hline \multicolumn{7}{|c|}{ Average weekly profits following UP markets } \\
\hline \multirow[t]{2}{*}{ Raw profit } & $0.1633^{* * *}$ & 0.0040 & 0.0007 & -0.0002 & 0.0001 & $-0.0014^{* *}$ \\
\hline & $(42.50)$ & (1.28) & $(0.49)$ & $(-0.14)$ & $(0.05)$ & $(-2.01)$ \\
\hline \multirow[t]{2}{*}{ CAPM alpha } & $0.1635^{* * *}$ & 0.0039 & 0.0009 & -0.0003 & 0.0001 & $-0.0012^{*}$ \\
\hline & $(43.18)$ & $(1.28)$ & $(0.65)$ & $(-0.21)$ & $(0.09)$ & $(-1.69)$ \\
\hline Fama-French & $0.1612 * * *$ & 0.0029 & 0.0007 & -0.0007 & -0.0003 & $-0.0013^{*}$ \\
\hline
\end{tabular}




\begin{tabular}{lllllll}
\hline alpha & $(45.85)$ & $(0.94)$ & $(0.50)$ & $(0.59)$ & $(-0.24)$ & $(-1.85)$ \\
\hline \multirow{2}{*}{ Raw profit } & $0.1485^{* * *}$ & -0.0022 & $-0.0026^{* *}$ & 0.0008 & 0.0014 & 0.0001 \\
& $(41.33)$ & $(-0.77)$ & $(-2.02)$ & $(0.67)$ & $(1.18)$ & $(0.13)$ \\
\hline CAPM alpha & $0.1490^{* * *}$ & -0.0023 & $-0.0028^{* *}$ & 0.0008 & 0.0013 & -0.0002 \\
& $(42.08)$ & $(-0.79)$ & $(-2.21)$ & $(0.69)$ & $(1.07)$ & $(-0.27)$ \\
\hline Fama-French & $0.1511^{* * *}$ & -0.0016 & $-0.0029 *$ & 0.0007 & 0.0014 & -0.0006 \\
alpha & $(45.95)$ & $(-0.56)$ & $(-2.31)$ & $(0.58)$ & $(1.23)$ & $(-0.87)$ \\
\hline
\end{tabular}

Note: $\left({ }^{* *}\right),\left({ }^{* *}\right),\left(^{*}\right)$ indicate significance at the $1 \%, 5 \%$ and $10 \%$ level, respectively. $t$-statistics are presented in parentheses.

Panel B illustrates that for the first period, the raw and the CAPM-adjusted profits following UP states are significant in week 1, sustain their significance in week 2-5 and become insignificant in longer horizons. After being accounted for the three factors, the profit prolongs its significance till week 6-9, and then weakly reverses in week 14-26, showing a sign of initial over-reaction and a price correction in stock prices. Especially, the profit following UP states is 2.24 per cent per week, rather higher the average profit of 1.54 per cent per week in Table 4. On the other hand, following DOWN states, the raw and the three-factor adjusted profits are insignificant in week 1 and in the subsequent months. The CAPM-adjusted profit is weakly significant in week 1 and become insignificant in all following months. These results show that the stream of insignificant profits following DOWN states offset the stream following UP states in Table 5, generating a stream of a significant profit in week 1 and insignificant profits in the subsequent months in Table 4.

Panel $\mathrm{C}$ shows that momentum does not occur in the second period following either UP or DOWN states. The raw and the risk-adjusted profits in week 14-26 following UP states and those in week 2-5 following DOWN states are significantly negative. Nevertheless, these values are economically small. Cooper et al. (2004) argue that these reversals may be caused by other factors instead of the price correction for the delayed overreaction.

In a nutshell, Table 4 and 5 indicate that momentum is related to market states: it follows market gains only in the period prior to the Lehmann shock; after the market declines or in the post-Lehmann shock period it does not exist. The profit stream following UP states is consistent with the over-reaction hypothesis.

\section{Conclusion and discussions}

Our initial results show that momentum occurs in the short-run. The most successful strategy that selects stocks based on their previous one-week returns and keeps them for one week earns 0.83 percent per week. This profit is still higher than transaction cost when a large value of trading is considered. The results from additional tests indicate that winner and loser returns are lowly persistent and highly volatile, but their strong correlation creates significant momentum profits. 
The results from further tests show that momentum is confined to small- and large-sized subsamples in the period before the Lehmann shock. Especially, it follows short-term market gains and is consistent with the over-reaction hypothesis. This implies that after realizing market gains, investors are more confident and overreact to news, which produces initial over-reaction and long-term reversals. However, the magnitude of reversals is very weak, which can be explained by the argument of Chui et al. (2010) on individualism. A survey by Geert Hofstede indicates that Vietnam is a collectivistic society with its individualism score of $20^{18}$. In addition, Ngo and Truong (2011) provide evidence on herding behavior, which implies the low individualism of the Vietnamese investors. Hence, the low individualism is likely to explain the weak reversal in the Vietnamese stock market. Put differently, the less individualistic investors-who act less like the overconfident/self-attribution biased ones tend not to make investment decisions that produce momentum profits and reversals in long-term horizons.

Similar to the findings of Chui et al. (2000) in the Asian markets in the pre-1997 crisis period, momentum does not exist after the Lehmann shock. This is due to the small difference between winner and loser returns, which might derive from the less confidence of investors following market declines.

\section{References}

Barberis, N., Shleifer, A., \& Vishny, R. (1998). A model of investor sentiment. Journal of Financial Economics, 49(3), 307-343. http://dx.doi.org/10.1016/S0304-405X(98)00027-0

Chordia, T., \& Shivalumar, L. (2002). Momentum, business cycle, and time-varying expected returns. The Journal of Finance 57(2), 985-1019. http://dx.doi.org/10.1111/1540-6261.00449

Chui, A.C.W, Titman, Sh., \& Wei, K.C.J. (2000). Momentum, Legal Systems and Ownership Structure: An Analysis of Asian Stock Markets. Working paper. Retrieved from http://ssrn.com/abstract=265848 or http://dx.doi.org/10.2139/ssrn.265848

Chui, A.C.W, Titman, Sh., \& Wei, K.C.J. (2010). Individualism and Momentum around the World. The Journal of Finance, 65(1), 361-392. http://dx.doi.org/10.1111/j.1540-6261.2009.01532.x

Conral, J., \& Kaul, G. (1998). An anatomy of trading strategies. Review of Financial Studies, 11(3), 489-519. http://dx.doi.org/10.1093/rfs/11.3.489

Cooper, M. J., Gutierrez Jr., R. C., \& Hameed, A. (2004). Market states and momentum. The Journal of Finance, 59 (3), 1345-1365. http://dx.doi.org/10.1111/j.1540-6261.2004.00665.x

Daniel, K., Hirshleifer, D., \& Subrahmanyam, A. (1998). Investor psychology and security market under- and overreactions. The Journal of Finance, 53(6), 1839-1885. http://dx.doi.org/10.1111/0022-1082.00077

DeBondt, W.F.M., \& Thaler R.H. (1985). Does the stock market overreact? The Journal of Finance, 40(3), 793-805. http://dx.doi.org/10.1111/j.1540-6261.1985.tb05004.x

${ }^{18}$ Retrieved from http://geert-hofstede.com/vietnam.html 
Du, D., Huang, Zh., \& Liao, B. (2009). Why is there no momentum in the Taiwan stock market? Journal of Economics and Business, 61(2), 140-152. http://dx.doi.org/10.1016/j.jeconbus.2008.06.001

Fama, E. F. (1970). Efficient capital markets: A review of theory and empirical work. The Journal of Finance 25 (2), 383-417. http://dx.doi.org/10.2307/2325486

Fama, E.F. (1991). Efficient Capital Markets: II. The Journal of Finance, 46 (5), 1575- 1617. http://dx.doi.org/10.1111/j.1540-6261.1991.tb04636.x

Fama, E.F., \& French, K.R. (1996). Multifactor explanations of asset pricing anomalies. The Journal of Finance, 51(1), 55-84. http://dx.doi.org/10.1111/j.1540-6261.1996.tb05202.x

Griffin, J.M., Ji, X., \& Martin, J.S. (2003). Momentum investing and business cycle risk: Evidence from pole to pole. The Journal of Finance, 58(6), 2515-2547. http://dx.doi.org/10.1046/j.1540-6261.2003.00614.x

Gutierrez Jr., R.C. \& Kelley, E. K. (2008). The long lasting momentum in weekly returns. Journal of Finance, 63(1), 415-447. http://dx.doi.org/10.1111/j.1540-6261.2008.01320.x

Hong, H., \& Stein, J.C. (1999). A unified theory of under-reaction, momentum trading and overreaction in asset markets. The Journal of Finance, 54(6), 2143- 2184. http://dx.doi.org/10.1111/0022-1082.00184

Jegadeesh, N., \& Titman, S. (1993). Returns to buying winners and selling losers: Implications for stock market efficiency. The Journal of Finance, 48(1), 65-91. http://dx.doi.org/10.1111/j.1540-6261.1993.tb04702.x

Jegadeesh, N., \& Titman, S. (2001). Profitability of momentum strategies: An evaluation of alternative explanation. The Journal of Finance 56, (2), 699-720. http://dx.doi.org/10.1111/0022-1082.00342

Jegadeesh, N., \& Titman S. (2011). Momentum. Working paper. Retrieved from SSRN: http://ssrn.com/abstract=1919226 or http://dx.doi.org/10.2139/ssrn.1919226

Lehmann, B.N. (1990). Fads, Martingales and Market Efficiency. Quarterly Journal of Economics, 105(1), 1-28. http://dx.doi.org/10.2307/2937816

Levine, R. (2001). International Financial Liberalization and Economic Growth. Review of International Economics 9(4), 688-702. http://dx.doi.org/10.1111/1467-9396.00307

Ngo, M. T., \& Truong, H. H. (2011). Herding Behavior in an Emerging Stock Market: Empirical Evidence from Vietnam. Research Journal of Business Management, 5(2), 51-76. http://dx.doi.org/10.3923/rjbm.2011.51.76

Nguyen, V., Tran, A., \& Zeckhauser, R. (2011). Insider Trading and Stock Splits. Working Paper. Retrieved from SSRN: http://ssrn.com/abstract=2024101 or http://dx.doi.org/10.2139/ssrn.2024101 


\section{Macrothink}

Asian Journal of Finance \& Accounting ISSN 1946-052X 2013, Vol. 5, No. 2

Rouwenhorst, K.G. (1998). International momentum strategies. The Journal of Finance, 53(1), 267 - 284. http://dx.doi.org/10.1111/0022-1082.95722

Rouwenhorst, K. G. (1999). Local return factors and turnover in emerging stock markets. The Journal of Finance, 54(4), 1439-1463. http://dx.doi.org/10.1111/0022-1082.00151

Truong, D.L, Lanjouw, G., \& Lensink, R. (2010). Stock-market efficiency in thin-trading markets: the case of the Vietnamese stock market. Applied Economics, 42, 3519-3532. http://dx.doi.org/10.1080/00036840802167350 